RESEARCH ARTICLE

\title{
Application of electrospun cellulose acetate nanofibre membrane based quasi-solid state electrolyte for dye sensitized solar cells
}

\author{
A.M.J.S. Weerasinghe ${ }^{1,4}$, M.A.K.L. Dissanayake ${ }^{1,4}$, G.K.R. Senadeera ${ }^{1,3, *}$, V.A \\ Senaviratne $^{2}$, C. A. Thotawatthage ${ }^{1,4}$ and J.M.K.W. Kumari ${ }^{1,4}$ \\ ${ }^{1}$ National Institute of Fundamental Studies, Hanthana Road, Kandy, Sri Lanka. \\ ${ }^{2}$ Department of Physics, Faculty of Science, University of Peradeniya, Peradeniya, Sri Lanka \\ ${ }^{3}$ Department of Physics, The Open University of Sri Lanka, Nawala, Nugegoda, Sri Lanka \\ ${ }^{4}$ Postgradutate Institute of Science, University of Peradeniya, Sri Lanka
}

Received: 14/05/2017; Accepted: 29/05/2017

\begin{abstract}
Dye Sensitized Solar Cells (DSSCs) are much more eco-friendly, low cost and easy to fabricate devices compared to silicon solar cells. In order to overcome their problems with safety and the long-term stability due to sealing problems, liquid electrolytes employed in these devices are replaced with quasi solid-state or gel electrolytes even though the overall efficiencies are somewhat lower. In this study DSSCs are fabricated and tested by replacing the conventional liquid electrolyte using a quasi-solid state electrolyte comprised of biodegradable electro spun cellulose acetate (CA) nanofibres. DSSCs fabricated with this quasi-solid state electrolytes showed an overall light to electricity conversion efficiency of $4.0 \%$ under the illumination of $100 \mathrm{~mW}$ $\mathrm{cm}^{-2}$ (AM 1.5). The corresponding values of short circuit current density $\left(\mathrm{J}_{\mathrm{sc}}\right)$, open circuit voltage $\left(\mathrm{V}_{\mathrm{oc}}\right)$ and the fill factor (FF) of this device were $9.83 \mathrm{~mA}$ $\mathrm{cm}^{-2}, 699.1 \mathrm{mV}$ and 0.58 respectively.
\end{abstract}

Keywords: Dye sensitized solar cells, nanofibres, polymer electrolytes.

\section{INTRODUCTION}

Dye Sensitized Solar Cells (DSSCs) are a low cost and simple alternative to conventional solar cells and considered as a promising solution for harvesting solar energy (Nazeeruddin et al., 2011). A typical DSSC isfabricated by sandwiching a semiconductor film associated with a sensitizer and a redox mediator in an electrolyte between twofluorine doped Tin oxide (FTO) conducting electrodes. When the devices are exposed to the sunlight, the photo excitation occurs in the sensitizer andelectrons are transferred to conduction band of the semiconductor oxide film, which is usually $\mathrm{TiO}_{2}$ and then to the conducting electrode (FTO) attached to the semiconductor and finally reached the opposite side of the device through an external circuit. The electron donation from the redox electrolyte regenerates the sensitizer by accepting the electrons from the counter electrode, which comes through the external circuit. However, these devices generally consist of a liquid electrolyte based redox mediator and therefore their wide spread commercialization is hindered, especially due to the problems associated with the leaking of the liquid electrolyte in these devices. Therefore, one of the solutions to overcome this problem is the replacement of the liquid electrolyte by an efficient quasi-solid state electrolyte. Most of the quasi-solid electrolytes are prepared with conventional non-biodegradable polymeric materials such as Polyethylene Oxide (PEO) and Polyacrylonitrile (PAN). Therefore, there is a great advantage in replacing these polymers with eco-friendly biodegradable polymeric materials such as cellulose, gelatin etc. Cellulose and its derivatives are natural polymers, which are made from glucose monomer units. Cellulose compounds are considered as an important structural material of plants and it is the most abundant organic polymer on Earth. Properties such as biodegradability, abundance, thermal stability and chemical resistance of Cellulose Acetate (CA) nanofibres have led to employ them in many biomedical applications, selfcleaning textiles andsmart fabrics, reinforced nano composites, and inareas such as biotechnology, agriculture, environmental engineering, defense and security, energy storage and generation(Chen et al.,2007; Han et al.; 2008, Konwarh et al. 2013)). In the context of fabricating nanofibres, electrospining technique is one of the simplest methods to produce nanofibres suitable for many applications. This was a method pioneered by Formahls in 1934 
patenting his apparatus for the production of "artificial filaments using electric charges" (Subbiah et al., 2005)..The basic apparatus of electrospining consists of a syringe pump, a drum collector and a high voltage dc power supply. The high electric field generated between the needle and the drum collector is used to eject droplets of polymer solution through the needle. The electrostatic force due to high potential overcomes the surface tension and the solvent evaporates forming dry fibres on the collector (Zhang et al., 2008) The morphology and properties of the electrospun nanofibres also depend on parameters such as pump flow, applied voltage, distance between the needle and collector drum, and solvent properties such as viscosity, surface tension, conductivity, and vapour pressure (Subbiah et al., 2005).

Therefore, by considering the above factors, we have explored the possibilities of fabricating of DSSC's using electrospun CA nanofibre based quasi solid-state electrolyte. Previously we have tested the performances of DSSCs consisting of quasi solid- state electrolyte with $\mathrm{CA}$ and sensitized by a natural dye (Weerasinghe et al, 2016) . However, due to some technical problems the composition of that electrolyte could not be used in the DSSCs with the commonly used RuN719 dye. Therefore, in this study, we have varied the composition of CA based quasi solid electrolyte and tested its performances in RuN719 dye sensitized DSSCs and promising solar cells performance was obtained. According to the best of ourknowledge, this may be the first report of the application of cellulose acetate nanofibre membrane in a quasisolid electrolyte suitable for $\mathrm{Ru} 9719$ dye sensitized DSSCs.

\section{EXPERIMENTAL}

\section{Materials}

Guanidinium thiocyanate, cellulose acetate and iodine chips $\left(I_{2}\right)$ with a purity greater than $97 \%$ were purchased from Fluka. Tetrapropyl ammonium iodide $\left(\mathrm{Pr}_{4} \mathrm{NI}\right)$, acetone and absolute ethanol were purchased from Aldrich. Fluorine doped $\mathrm{SnO}_{2}$ layered (FTO) glass (sheet resistance $7 \Omega / \mathrm{sq}$ ) and Ruthenium dye (N719) [RuL2 (NCS) 2:2TBA where L = 2, 2'-bipyridyl4,'-dicarboxlylic acid; TBA= tertrabutylamonium] were purchased from Solaronix SA. Dimethylsulfoxide (assay 99.99\%) was purchased from Fisher scientific.

\section{$\mathrm{TiO}_{2}$ electrode preparation}

At first compact layer of $\mathrm{TiO}_{2}$ with approximately $100 \mathrm{~nm}$ thickness, was prepared using a solution prepared according to the following method. $5 \mathrm{ml}$ of acetic acid and $30 \mathrm{ml}$ of ethanol were added to $5 \mathrm{ml}$ of propan-1-ol which was kept in a water bath at $0{ }^{\circ} \mathrm{C}$ and magnetically stirred for about 30 minutes. Then 5 $\mathrm{ml}$ of titanium isopropoxide was added by drop wise to the above mixture and further stirred for an hour. Resulting solution was spin coated at 3000 RPM for 1 min on previously cleaned FTO conducting glass and sintered at $450{ }^{\circ} \mathrm{C}$ for 45 minutes. In order to fabricate a thick and porous nanocrystalline $\mathrm{TiO}_{2}$ film, a colloidal $\mathrm{TiO}_{2}$ suspension was prepared by mixing $1 \mathrm{ml}$ of $0.1 \mathrm{M}$ nitric acid with a drop of emulsification reagent Triton X-100 and $0.05 \mathrm{~g}$ of Polyethlene glycol (PEG-1000) in an agate mortar. The mixture was then ground for about 30 minutes until it became a homogeneous mixture. The $\mathrm{TiO}_{2}$ electrode was made by spreading the above mixture on the FTO glass plates by doctor blade method and sintered the electrode for 45 minutes at $450{ }^{\circ} \mathrm{C}$. After cooling to room temperature, the electrodes were immersed in a $0.04 \mathrm{M}$ Titanium Tetracloride $\left(\mathrm{TiCl}_{4}\right)$ solution for 24 hours at $40{ }^{\circ} \mathrm{C}$ and sintered again according to the procedure mentioned above. Finally, the electrodes were immersed in an ethanolic $0.3 \mathrm{mM}$ solution of N719 dye of at room temperature and left for 24 $\mathrm{h}$ to complete the dye adsorption

\section{Electrolyte preparation}

It was observed that when the dyed photoanode was immersed in the electrolyte solution, some of the dyes undergo dissolution into the electrolyte. In order to prevent this problem, 1 $\mathrm{ml}$ of an ethanolic dye solution containing 0.3 $\mathrm{mM}$ Ruthenium Dye N719 was used as the primary electrolyte solvent. Then $0.1566 \mathrm{~g}$ tetrapropyl ammonium iodide $\left(\mathrm{Pr}_{4} \mathrm{NI}\right)$ and 0.0118 $\mathrm{g}$ guanidinium thiocyanate were added to the above ethanolic dye solution and magnetically stirred overnight. The weight of the iodine was maintained at one tenth of the total mole amount of thetetrapropyl ammonium iodide. Guanidinium thiocyanate was added as an additive to the electrolyte which is widely used to increase the open circuit voltage $\left(\mathrm{V}_{\mathrm{oc}}\right)$ of the solar cells and the stability of the electrolyte during the I-V measurements ( $\mathrm{Yu}$ et al. 2010; Zhang et al. 2009). 


\section{Cellulose acetate nanofibre preparation}

Cellulose acetate nanofibres were prepared by using the Nabond electro spinning system ( $\mathrm{Na}$ Bond Technologies, Hong Kong). The electro spinning solution was prepared by mixing a solution of cellulose acetate powder $(1.0 \mathrm{~g})$ in a $2.0 \mathrm{ml}$ of Dimethyl Sulfoxide (DMSO) and 4.0 $\mathrm{ml}$ of acetone and magnetically stirring overnight. The resulting solution was used for electro spinning with a $10 \mathrm{kV} \mathrm{dc}$ voltage applied between the spinneret and the drum collector. The syringe pump flow rate was maintained at 2 $\mathrm{ml} / \mathrm{h}$. The electrospun cellulose acetate nanofibres were collected on a grounded polished platinum plate attached to the drum collector rotating at 415 RPM. The distance between the collector and the needle tip was fixed at $10 \mathrm{~cm}$ and the process continued for 10 minutes to obtain a uniform layer of CA nanofibres formed on the platinum electrode.

\section{Fabrication of Dye Sensitized Solar Cells}

A drop of the electrolyte solution was carefully placed on the cellulose acetate nanofibre film coated on platinum plate and left for several minutes for the fibre film to absorb the electrolyte solution and form a quasi solid state (gel) electrolyte. The excess electrolyte was carefully wiped off to remove the free liquid electrolyte left on the platinum electrodes. Dye sensitized solar cells were fabricated in the configuration $\mathrm{FTO} / \mathrm{TiO}_{2} /$ dye/ electrospun nano fibre membrane gel electrolyte/Pt/FTO.

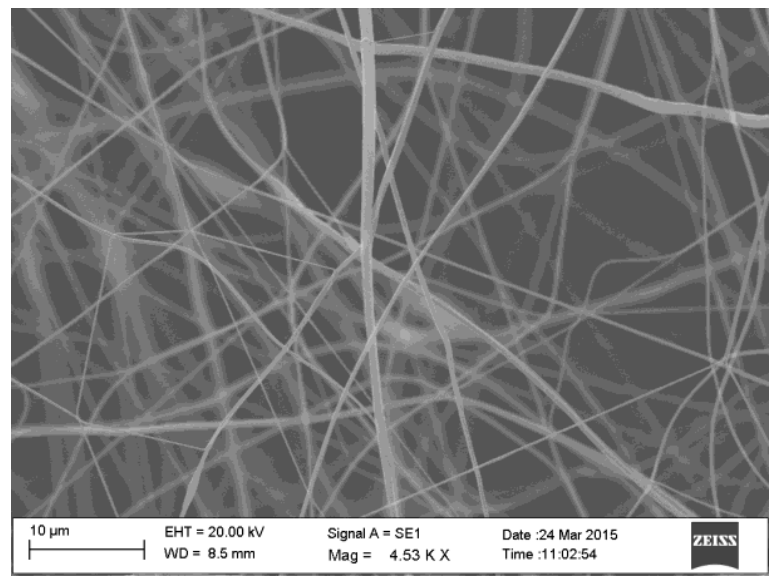

\section{Characterization}

The ionic conductivity of the liquid electrolyte was measured by the AC complex impedance method using a Metrohm Autolab Potentiostat/ Galvanostat PGSTAT $128 \mathrm{~N}$ in the frequency range of $100 \mathrm{~Hz}$ to $1 \mathrm{MHz}$. For these measurements, the electrolyte solution was sandwiched between two stainless steel electrodes and the measurements were done at room temperature. The same equipment was used for electrochemical impedance measurements of the DSSCs under the illumination of $100 \mathrm{~mW}$ $\mathrm{cm}^{-2}$. Dark I-V measurements and Bode phase plots were also obtained using the same instrument.

The J-V characteristics of the fabricated solar cells were measured under illumination of 100 $\mathrm{mWcm}^{-2}$ using a Xenon 500 lamp with AM 1.5 filter for sunlight simulation in a set up Keithley 2000 multimeter and a potentiostat /galvanostat HA-301. The surface morphology of the electrospun cellulose acetate nanofibres were analyzed by Zeiss EVOLS15 scanning electron microscope after applying a gold coating. The average fibre diameter was determined from SEM images.

\section{RESULTS AND DISCUSSION}

In DSSC performance, the electrolyte plays a critical role by transferring charged redox species between the photo anode and the counter electrode. The ionic conductivity of the electrolyte is, therefore, an important parameter. The room temperature ionic conductivity of the

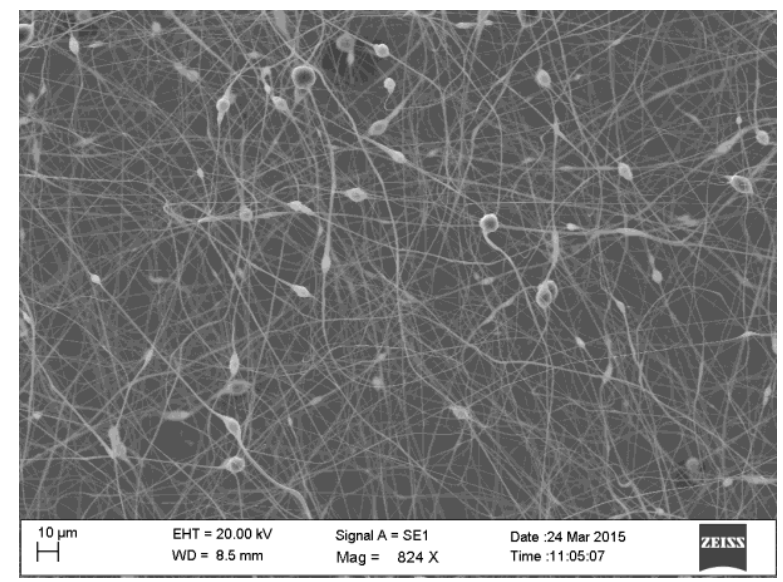

Figure 1: (A) Scanning electron micrograph of electrospun Cellulose Acetate nanofibres and (B) Zoomed out view of nanofibres showing bead like structures. 
liquid electrolyte extracted from impedance measurements is $7.45 \mathrm{mS} \mathrm{cm}^{-1}$.

The morphology of the electrospun CA nanofibre surface depends on processing parameters such as the distance between the tip and the collector, applied high voltage and the polymer concentration (Anitha et al.,2013; Liu et al., 2006). As shown in figure $1 \mathrm{~A}$ the nanofibres are cylindrical in shape and show bead free smooth surface. The average diameter of the nanofibresis estimated to be approximately $600 \mathrm{~nm}$. However, on higher resolution, several elongated spindle like beads were observed in the sample (figure 1B). This indicates the resistance of the jet to extensional flow in the process of electrical potential driven fibre formation (Liu et al., 2006).

The Fill Factor (FF) and the overall light to electrical energy conversion efficiency $(\eta)$ of the DSSC were calculated using the following equations.

$F F=\frac{V_{\max } \times J_{\max }}{V_{O C} \times J_{S C}}$

$$
\begin{aligned}
\eta(\%) & =\frac{V_{\max } \times J_{\max }}{P_{\text {in }}} \times 100 \\
& =\frac{V_{O C} \times J_{S C} \times F F}{P_{\text {in }}} \times 100,
\end{aligned}
$$

where $\mathrm{J}_{\mathrm{SC}}$ is the short circuit current density ( $\mathrm{mA}$ $\left.\mathrm{cm}^{-2}\right), V_{\mathrm{OC}}$ is the open circuit voltage $(\mathrm{mV}), \mathrm{P}_{\text {in }}$ is the incident light power, and $\left.\mathrm{J}_{\max }(\mathrm{mA} \mathrm{cm})^{-2}\right)$ and $\mathrm{V}_{\max }(\mathrm{mV})$ are the current density and voltage at the point of maximum power output on the $\mathrm{J}-\mathrm{V}$ curves respectively.

Photocurrent density vs voltage (J-V) characteristic curve of a DSSC based on CA nanofibrequasi solidelectrolyte measured under AM 1.5 simulated sunlight in the ambient atmosphereis shown in Figure 2 and important DSSC parameters extracted from it are tabulated in Table 1.

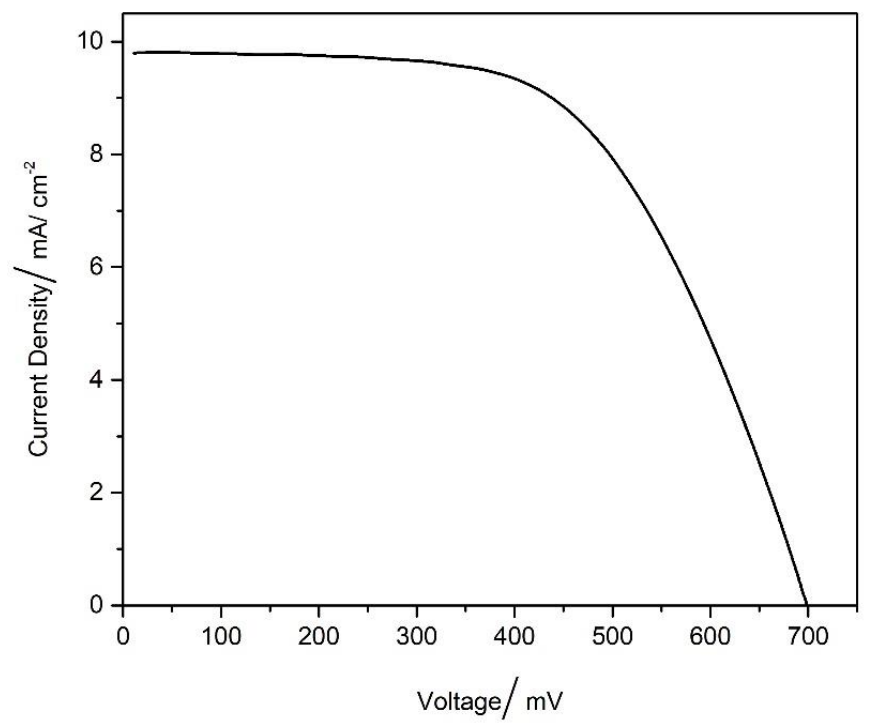

Figure 2: J-V Characteristics of the optimized DSSC fabricated with cellulose acetate nano fiber based quasi solid state (gel) electrolyte.

Table 1: Important cellparameters of the DSSC based on CA nanofibre gel electrolyte.

\begin{tabular}{|c|c|c|c|}
\hline $\mathbf{J}_{\mathbf{s c}}\left(\mathbf{m A ~ c m} \mathbf{~ c m}^{-2}\right)$ & $\mathbf{V}_{\mathbf{o c}}(\mathbf{m V})$ & $\mathbf{F F}$ & $\boldsymbol{\eta} \%$ \\
\hline 9.83 & 699.1 & 0.58 & 4.0 \\
\hline
\end{tabular}


Table 2: Charge transfer resistance values extracted from equivalent circuit analysis of Nyquist plots for the two types of DSSCs.

\begin{tabular}{|c|c|c|c|}
\hline $\mathbf{R}_{\mathbf{S}}(\mathbf{\Omega})$ & $\mathbf{R}_{\mathbf{1 C T}}(\mathbf{\Omega})$ & $\mathbf{R}_{\mathbf{2 C T}}(\mathbf{\Omega})$ & $\mathbf{R}_{\mathbf{3 C T}}(\mathbf{\Omega})$ \\
\hline 11.9 & 19.4 & 13.0 & 3.4 \\
\hline
\end{tabular}
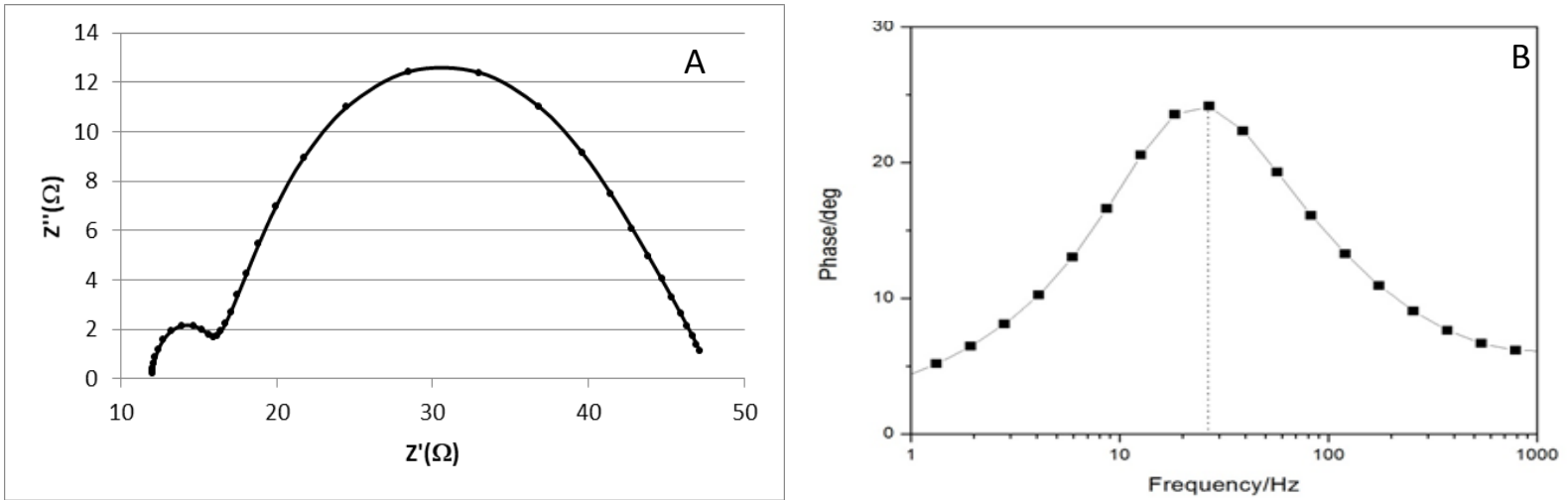

Figure 3: (A)Nyquist plots of DSSCs derived from EIS analysis for cellulose acetate based quasi solid state electrolyte. (B) Bode phase diagram used for the determination of electron life time.

The interfacial recombination kinetics of the electrolyte was measured by using Electrochemical Impedance Spectroscopy (EIS) method. The Nyquist plot is given in Figure 3A and Bode phase diagram for the determination of electron life time is shown in Figure $3 \mathrm{~B}$. The series resistance $\left(R_{s}\right)$, charge transfer resistance of the Pt/electrolyte $\left(\mathrm{R}_{1 \mathrm{CT}}\right)$, charge transfer resistance of the $\mathrm{TiO}_{2} /$ electrolyte $\left(\mathrm{R}_{2 \mathrm{CT}}\right)$ for gel and liquid electrolyte, tri-iodide ion diffusion of the electrolyte $\left(\mathrm{R}_{3 \mathrm{CT}}\right)$ extracted using equivalent circuit are given in Table 2.

The electron life time $(\tau)$ of the DSSC is $6.00 \mathrm{~ms}$ which was obtained by analyzing the Bode phase plot of the EIS spectrum (Figure 3B) where the frequency peak $\left(\mathrm{f}_{\max }\right)$ was observed at $26.5 \mathrm{~Hz}$.

\section{CONCLUSION}

Cellulose acetate (CA) nanofibres have been successfully prepared as a thin membrane by electro spinning technique. These nanofibres were used to form a quasi-solid state (gel) electrolyte by incorporating a liquid electrolyte in the interfiberal matrix space. This biodegradable and eco friendly gel electrolyte was used to fabricate DSSCs. The fabricated DSSC has a light to electricity conversion efficiency of $4.0 \%$ at an incident light intensity of $100 \mathrm{~mW} \mathrm{~cm} \mathrm{~cm}^{-2}$ with a $1.5 \mathrm{AM}$ filter. The open circuit voltage $\left(\mathrm{V}_{\mathrm{oc}}\right)$, short circuit current density $\left(\mathrm{J}_{\mathrm{sc}}\right)$, and fill factor for the fabricated solar cells are $9.83 \mathrm{~mA} \mathrm{~cm}{ }^{-2}, 699.1 \mathrm{mV}$, and 0.58 respectively. These results suggest that cellulose acetate nanofibres have the potential to be developed as a host matrix to prepare a quasi solid-state gel electrolyte in DSSCs.

\section{REFERENCES}

Anitha, S., Brabu, B., Thiruvadigal, D. J., Gopalakrishnan, C., Natarajan, T. (2013). Optical, Bactericidal and Water Repellent Properties of Electrospun Nano-Composite Membranes of Cellulose Acetate and $\mathrm{ZnO}$. Carbohydrate Polymers 97: 856-863.

Chen, C., Wang, L,.Huang, Y. (2007). Electrospinning of Thermo-Regulating Ultrafine Fibers Based on Polyethylene Glycol/cellulose Acetate Composite. Polymer 48: 5202-5207.

Han, S., Youk, J. H., Min, K., Kang, K. D., Park, W.H. (2008). Electrospinning of Cellulose Acetate Nanofibers Using a Mixed Solvent of Acetic Acid/water: Effects of Solvent Composition on the Fiber Diameter. Materials Letters 62: 759-762.

Haas, D., Heinrich, S., Greil, P. (2009). Solvent Control of Cellulose Acetate Nanofibre Felt Structure Produced by Electrospinning. Journal of Materials Science 45: 1299-1306.

Konwarh, R., Karak, N., Misra, M. (2013) Electrospun Cellulose Acetate Nanofibers: The Present Status and Gamut of Biotechnological Applications. Biotechnology Advances 31: 421437.

Nazeeruddin, M.K., Baranoff, E., Grätzel. M. (2011). Dye-Sensitized Solar Cells: A Brief Overview. Solar Energy 85: 1172-1178. 
Subbiah, T., Bhat, G.S., Tock, R.W., Parameswaran, S., Ramkumar. S.S. (2005). Electrospinning of Nanofibers. Journal of Applied Polymer Science 96: 557-569.

Weerasinghe, A,M,J.S, Thotawattage, C.A., Dissanayake, M.A.K.L., Senadeera, G.K.R. (2009). Eco-friendly dye sensitized solar cells made with natural pigments from fire fierm and biodegradable polymer electrolyte. Conference proceedings, South Asian Symposium on Sustainable Environment Management, 17-18 March, 2016, University of Peradeniya. Sri Lanka.19-21.
Yu, Z., Gorlov, M., Boschloo, G., Kloo, L. (2010).Synergistic Effect of NMethylbenzimidazole and GuanidiniumThiocyanate on thePerformance of Dye-Sensitized Solar Cells Based on Ionic Liquid Electrolytes.Journal of Physical Chemistry 114: 22330-22337.

Zhang, C., Huang, Y., Huo, Z., Chen, S., Dai, S. (2009). Photoelectrochemical Effects of GuanidiniumThiocyanate on Dye-Sensitized Solar CellPerformance and Stability. Journal of Physical Chemistry 113: 21779-21783. 